\title{
ORIGINALISMO, INTERPRETAÇÃO CONSTITUCIONAL E SEUS SENTIDOS POLÍTICOS
}

\author{
ORIGINALISM, CONSTITUTIONAL HERMENEUTICS AND POLITICAL MEANINGS
}

\section{Lauro Ericksen}

\begin{abstract}
Bacharel, Mestre e Doutor em Filosofia pela Universidade Federal do Rio Grande do Norte (UFRN) Bacharel em Direito pela Universidade Federal do Rio Grande do Norte (UFRN) Especialista em Direito e Processo do Trabalho pela Universidade Cândido Mendes - RJ Professor da Pós-Graduação do Centro Universitário Unifacex Oficial de Justiça Avaliador Federal TRT 21

E-mail: lauroericksen@yahoo.com.br
\end{abstract}

Recebido em: 12/11/2018

Aprovado em: 16/03/2019

RESUMO: Trata do originalismo, método hermenêutico norte-americano de cariz histórico. Objetiva escrutinar sentido original, atendo-se a sua força interpretativa semântica, valendo-se, para tanto, da verificação de sua inquirição histórica como escopo interpretativo-normativo. Propõe o debate político inserido no contexto interpretativo constitucional como mote do desenvolvimento dos métodos hermenêuticos, asseverando que o originalismo se alinha ao espectro conservador. Metodologicamente, vale-se do viés empirista e epistemológico de sua inquirição histórica, para o alcance do sentido original pretendido. Considera que o originalismo possui uma sólida premissa histórica em oposição a interpretações extratextuais. Conclui que o originalismo é uma fonte substancial de interpretação em apego a lei, consolidada pela leitura textual de suas linhas.

Palavras-chave: Direito Constitucional; Constitucionalismo Norte-Americano; Hermenêutica; Originalismo; Semântica.

\begin{abstract}
The paper discusses the originalism, a historical north-American hermeneutical method. It intends to scrutinize the original meaning showing its semantic hermeneutical process, being able to process its view with such a normative-interpretative historical inquiry of constitutional dispositions. It proposes the political debate, involving sub-repetitious issues, inserted inside the constitutional background as a pivotal element of hermeneutics and constitutional interpretations, verifying that originalism is aligned with conservative manners. As a major method, it focuses on empiricist and epistemological way of historical inquiry to further accomplish to capture the intended original meaning. It concludes that the originalist theory has a persuasive historical premise in opposition to extratextual interpretations. It concludes originalism is a substantial source of constitutional textual tools; it is a method attached to its text and its history.
\end{abstract}

Key-Words: Constitutional Law; American Constitutionalism; Hermeneutics, Originalism, Semantics. 
SUMÁRIO: Introdução; 1 Originalismo, Sentido Original e Inquirição Histórica; 1.1 A Força Semântica da Hermenêutica Constitucional do Originalismo; 1.2 Inquirição Histórica e suas Derivações: Da Indeterminabilidade à Epistemologia Empírica; 2 O Originalismo e seus Aspectos Políticos Conservadores; Considerações Finais. Referências.

\section{INTRODUÇÃO}

O originalismo é uma teoria hermenêutica constitucional, de viés histórico, pouco conhecida nos meandros acadêmicos brasileiros, embora seja de grande expressão e prestígio no direito americano. Haja vista a sua grande influência e a sua imensa importância para o estudo hermenêutico constitucional como um todo, e sua quase que completa ignorância no debate acadêmico brasileiro, faz-se mister tecer algumas considerações ao seu respeito, e como ela pode ser de grande utilidade prática para a resolução os casos mais complexos e espinhosos da história constitucional hodierna, ainda que, metodologicamente, o artigo em tela não se proponha a analisar casuisticamente nenhuma situação.

De maneira propedêutica e bastante sucinta para os intentos introdutórios aqui apresentados, o originalismo pode ser descrito como a teoria que busca uma interpretação da constituição em consentâneo com o seu "sentido original" (ou, em sua língua originária, original meaning). Assim, o originalismo indica que o texto constitucional, e, consequentemente, toda e qualquer interpretação (ou provisão hermenêutica que possa dele ser derivada, extraída ou conjecturada), possui um sentido estático. Por sentido estático se deve compreender que o texto constitucional é bastante em si mesmo, não apenas para o seu tempo, bem como para as gerações vindouras e também para as gerações que virão depois dela. É a estática-semântica contida no próprio texto que garante que o sentido original é o mais apto a servir como espeque teóricofundacional para qualquer decisão jurisdicional ou qualquer interpretação jurídica que possa vir a ser gerada.

Nessa perspectiva, é interessante deixar assentado, desde a introdução do trabalho, o empenho "desbravador" e "desafiador" do conteúdo trabalhado, haja vista soar quase que "herético" propor, ao mesmo tempo, uma interpretação "estaticamente contida" da constituição, a qual desaguará, inarredavelmente, em uma proposta "conservadora". Dessa feita, as probabilidades de o conteúdo por ora abordado soarem "reacionárias são absurdamente grandes, isso sem falar na possibilidade de o artigo ser rechaçado em prol de postulados vagos e pouco efetivos, calcados na onipresente "justiça social" ou no "progresso liberal". Afinal, esses dois termos servem, atualmente, para justificar quase que qualquer coisa e para se opor a quase tudo que não seja apoiado ou defendido pelo estabilishment jurídico dominante (leia-se: neoconstitucionalismo liberal, e suas vertentes).

Retomando, há de se indicar que, além do "sentido original" de interpretação estática trazida pela doutrina do originalismo, o artigo em desenvolvimento tem como escopo correlato a necessidade de se trazer para o debate um viés ideológico-político inarredável: o conservadorismo inerente a uma interpretação originalista do texto constitucional. Alguns intérpretes e juristas mais puristas podem indicar que o conservadorismo não é ínsito ao originalismo, e sim um consectário lógico do tradicionalismo, esse sim seria o resultado mais imediato de um resgate original do texto constitucional. Ainda que esse debate (entre tradicionalismo e conservadorismo) seja prolífico, e deveras interessante, para os intentos primordiais e mais básicos de uma apresentação mais acessível da teoria do originalismo, o artigo em tela se focará basicamente em pressupostos do conservadorismo como resultado direto de tal produção hermenêutica. Ou seja, aquilo que pode ser compreendido como "tradicionalismo" será tratado, doravante, como conservadorismo, ou em uma acepção técnica mais apurada, conservadorismo histórico, já que seu alcance depende, 
necessariamente, de um resgate histórico adequado, ao corretivo de invalidade ou malversação de sua utilização por meio de um desvirtuamento intencional. Não obstante, há de se observar que se deixará o mencionado embate em segundo plano e para um aprofundamento posterior para aqueles que se interessarem pelo tema, e, porventura, desejarem adentrar um pouco mais nessa seara.

Metodologicamente, é importante ressaltar que o trabalho em desenvolvimento não se furta em trabalhar com a réplica progressista (ou não-originalista) de vários detratores da perspectiva originalista, desde a sua gênese com Brest, até mesmo com as críticas mais recentes, indicadas por Balkin, Whittington ${ }^{1}$, Dworkin dentre outros. Assim, é importante compreender que a análise do originalismo está ancorada na perspectiva enunciada de Scalia (1989, p. 849) que suas indicações são as menos danosas, ou, em suas palavras estritas, o originalismo é "um mal menor" (a lesser evil). Desse modo, o texto como um todo busca sempre sopesar as opiniões que divergem do originalismo, afinal, não há uma teoria de interpretação constitucional que seja perfeita e acabada em si mesma, aliás, essa nem mesma é a pretensão do originalismo, o qual, mesmo com suas possibilidades e limitações, ainda se apresenta como a melhor forma de hermenêutica constitucional disponível. De modo sintético, há de se indicar que a abordagem metodológica operada se calca em uma apresentação pouco convencional do constitucionalismo (ao menos para os padrões brasileiros) e que o seu intento mais básico e evidente é provocar o questionamento dos atuais limites da abordagem liberal-progressista da hermenêutica constitucional alicerçada em mutações constitucionais obtusas ou transformações sociais corriqueiras e efêmeras, em detrimento da possibilidade de uma fundação interpretativa mais perene e confiável. Assim, há de se apresentar que o originalismo não é a possibilidade hermenêutica-constitucional perfeita, ou dotada de elementos constitutivos inarredavelmente inabaláveis, ela é apenas a alternativa mais substancial e sólida para as questões constitucionalmente mais complexas e desafiadoras.

Didaticamente, o trabalho em relevo se divide, além da presente introdução, em mais três seções, incluindo-se aí as conclusões finais a título de fechamento do tema tratado. A seção subsequente apresenta os dois tópicos centrais do método originalista: o sentido original e a inquirição histórica utilizada para se apreender tal sentido. Essa seção tem como escopo primordial apresentar os elementos mais básicos do originalismo em linhas mestras e acaba por ser dividida em duas subseções. A primeira subseção trata da força semântica extraída do texto constitucional utilizada para embasar a solidez interpretativa do sentido original. A segunda subseção abre caminho para a inquirição histórica do originalismo, explicando conceitos de inquirição interpretativa e normativa para chegar aos preceitos empíricos e epistemológicos de sua indeterminabilidade contida, uma de suas características mais evidenciadas. A terceira seção do trabalho se dedica a fazer a conexão inarredável e necessária entre os aspectos políticos e a interpretação originalista do texto constitucional, para tanto, foca-se na fundamentação da legitimidade interpretativa do originalista, atrelada ao próprio texto e ao contexto histórico para daí extrair seus desdobramentos jurídicos e políticos. As considerações finais findam por dar uma conclusão aos temas afeitos ao originalismo, apresentando-o como um método hermenêutico de cariz histórico, fazendo as interconexões políticas em seu viés de compreensão conservador e tradicionalista.

\section{ORIGINALISMO, SENTIDO ORIGINAL E INQUIRIÇÃO HISTÓRICA}

A seção em desenvolvimento possui dois escopos primordiais. O primeiro deles diz respeito a um ligeiro aprofundamento no conceito de originalismo, tal como sucintamente posto na introdução, ressaltando a noção primordial de sentido original tal qual debatido no direito norte-

\footnotetext{
${ }^{1}$ Whittington (2011, p. 38) se considera um originalista (e um textualista), mas atrelado a uma corrente não conservadora do originalismo, denominada de originalismo pluralista, daí a sua inclusão no rol de críticos da vertente originalista esposada nesse trabalho, e advogada por Scalia, por exemplo.
}

Revista de Direito Brasileira | Florianópolis, SC | v. 22 | n. 9 | p. 50-65 |Jan./Abr. 2019 
americano. O segundo objetivo elementar diz respeito à ao tratamento dado à inquirição histórica como elemento metodológico imprescindível para a contextualização interpretativa e normativa do originalismo. O sentido original a ser perseguido pelo aplicador do Direito, e, consequentemente, por todo o intelectual que porventura se debruce sobre o texto constitucional, está encravado nos meandros históricos, de modo que a perquirição desses meandros depende metodologicamente dessa empreitada. Assim, tal perspectiva de inquirição deve ser operacionalizada de modo empírico, à lição de ser acusada de ser um veículo subjetivista por excelência, perdendo-se em divagações pouco objetivas do que é a História correlata ao texto constitucional e qual a legitimidade que pode ser extraída dessa forma de inquirição, já que o sentido original dela derivará de modo inequívoco.

Existem várias definições básicas de originalismo, uma delas o elenca como um método de interpretação (O'NEILL, 2007, p. 112), uma forma de enquadramento hermenêutico do texto constitucional segundo pressupostos descritos "originalmente" nesse mesmo excerto linguísticotextual. A partir dessa definição simples, já se percebe que o tex to constitucional guarda o próprio sentido a ser perseguido pelo hermeneuta. Essa breve explicação vai ao encontro do que Antonin Scalia (2016, p. 23) entende que deve ser a função do sentido original no contexto do originalismo, não se submetendo às expectativas que os membros do Legislativo imaginavam sobre o uso de suas palavras e frases. Muito mais que isso, o originalismo privilegia a importação semântica das palavras e das frases promulgadas na Constituição.

Essa proposição do que é originalismo pode ser mais bem destilada em três elementos fulcrais. O primeiro deles enuncia que o texto legal deve ser interpretado de acordo com o sentido original. O segundo elemento assevera que o sentido original de um termo valorativo (axiologicamente relevante) é extensivo em concomitância com as aplicações em geral que ele teria tido no momento da promulgação, por meio do importe semântico. Ademais, o último elemento de fulcro propõe que um termo valorativo em um texto legal deve ser interpretado de acordo com as aplicações comuns à época da promulgação.

O primeiro elemento é autoexplicativo, no entanto os outros dois parecem muito similares, podendo ser mais bem destrinchados. O segundo elemento pontua que há uma correspondência de extensão entre a compreensão do sentido original na época da promulgação e a sua assimilação hodierna. Já o terceiro elemento firma sua carga hermenêutica no tempo da promulgação, já que não há uma garantia perene que alguns setores da sociedade não tenham planejado o desmonte conceitual de alguma particularidade do sentido original a ser buscado, de modo que ele deverá ser resgatado diretamente do contexto histórico, sem nenhuma correspondência efetiva com o tempo atual. É justamente nesse último ponto que reside o resgate de compreensões conservadoras, e que usualmente são rechaçadas por teóricos contrários ao originalismo.

Outra definição bastante útil define o originalismo como uma família de ideias e práticas que alocam a autoridade do conteúdo de provisões legais em sentidos originários que prevalecem atualmente desde o tempo em que o texto constitucional foi promulgado (PRIMUS, 2008, p. 186). Nessa definição, o originalismo não é propriamente uma teoria, e sim um aglomerado de remissões teóricas e de comandos práticos a serem erigidos da autoridade constitucional contida num sentido originariamente proposto desde a criação do texto constitucional. Avançando no estudo conceitual do originalismo, há de se trazer uma definição mais sintética e didática, a qual aduz que, no originalismo, a única fonte de princípios e normas constitucionais é o entendimento (ou o sentido) original do texto da Constituição por si mesma (GOLDFORD, 2005, p. 99). Em última instância, o originalismo pode ser considerado uma forma de compreender o texto constitucional através da busca de um sentido original, contido numa busca (inquirição) histórica de tais balizas.

O primeiro autor a se referir a essa teoria pelo nome a ela convencionado foi Paul Brest (1981, p. 90) ao enunciar que por originalismo, "compreende-se a abordagem familiar à adjudicação constitucional que acorda em se conectar a autoridade do texto constitucional ou às intenções daqueles que a redigiram". Essa é a primeira passagem acadêmica que o termo 
"originalismo" (por vezes utilizado também como "interpretação originalista" a partir de então) foi cunhado, sendo importante destacar que termos que remetem a essa teoria, tais quais, entendimento original, intenções originais ou compreensão original já haviam sido utilizadas anteriormente em decisões ou posicionamentos jurisdicionais.

Ademais, o termo "sentido original" (um dos elementos basilares do originalismo) foi usado numa decisão judicial em 1966 na Suprema Corte Americana, no julgamento do caso Harper vs.Virginia State Bd. of Elections ${ }^{2}$, e desde então tais termos foram sendo cada vez mais utilizados para se referir à limitações constitucionais ao poder interpretativo e inovador dos magistrados perante o próprio texto da Constituição. Em decisões da mesma Corte, o termo "originalista" só veio a ser utilizado em 1995 no caso Roper vs. Simmons ${ }^{3}$, em decisão do Justice ${ }^{4}$ Scalia, e o termo "originalismo", por seu turno, só foi utilizado em 2005, no caso Van Orden vs. Perry ${ }^{5}$, em decisão do Justice Stevens. Salientando-se que em todos os casos levantados como exemplos históricos, a terminologia remetente ao originalismo foi utilizada seguindo-se premissas de posicionamentos dissonantes ao entendimento que estava sendo seguido, qual seja, o da evolução interpretativa modificativa constitucional.

Retomando a noção inicialmente dada por Brest sobre originalismo é importante denotar que mais do que explanar o termo ele acaba por criar uma celeuma ao bifurcar a possibilidade de interpretação entre a autoridade do texto constitucional e a intenção dos redatores do texto constitucional (GOLDFORD, 2005, p. 108). Não se sabe ao certo se esse resultado era pretendido ou não por Brest, tal debate é um tanto quanto incipiente, uma vez que, ao cunhar o termo, Brest estava visando atacar os intérpretes conservadores do texto constitucional, e, não propriamente, precipuamente tinha o intento de criar um novo arcabouço conceitual para essa metodologia hermenêutico-constitucional. Ou seja, ele estava tecendo uma crítica, e seus opositores se aproveitaram do pretenso ataque para capitalizar sobre o termo recém-criado, adotando-o.

A partir da criação do termo por Brest o originalismo foi se desenvolvendo e criando várias ramificações conceituais de modo que não existe um só conceito que venha a ser derradeiro sobre ele, havendo variações em suas definições, as quais vão desde uma aproximação do legalismo estrito, até mesmo a proposição a ser defendida no decorrer do artigo, a qual se apega a uma inquirição histórica do texto original como forma de avivamento do tradicionalismo a ele ínsito, algo a ser mais bem conectado e desenvolvido adiante, em tópico próprio.

Essa forma de originalismo (referido por vezes como "originalismo do sentido original" ou "do sentido público original") é a defendida pelo já mencionado Justice Antonin Scalia, e que se tornou prevalente na Suprema Corte Americana em suas decisões mais recentes (BENNETT; SOLUM, 2016, p. 31). Seu foco é no textualismo forte ${ }^{6}$ e numa intensificação do conteúdo semântico de cláusulas operativas, em detrimento de posicionamentos teleológicos (SCALIA; GARNER, 2012, p. 427). A escolha pelo conteúdo semântico já descrito no próprio texto constitucional elimina margens interpretativas inovadoras e que persigam ideais fora do contexto histórico em que o texto foi formulado. Ou seja, só há duas balizas que são igualmente válidas para o originalismo, o próprio tex to constitucional, ou o sentido original dele mesmo abstraído, qualquer outra ponderação que suplante ou desvie desses nortes será inconstitucional e desarrazoada.

\footnotetext{
${ }^{2}$ Vide 383 U.S. 663 at 671 (1966)

3543 U.S. 551 at 626 (1995)

${ }^{4}$ A partir de uma tradução livre, Justice no direito americano é o equivalente ao ministro do Supremo Tribunal Federal.

5545 U.S. 677 at 729 (2005).

${ }^{6}$ Se há alguma ironia presente no desenvolvimento do trabalho em tela ela pode ser de plano identificada na correlação feita entre o textualismo forte (de matiz esquerdista, no espectro político) e o originalismo (o qual prima elo tradicionalismo e por um perfil conservador em seus intentos). Assim, como já denotou acrisolada e similarmente William N. Eskridge Jr. (2013, p. 532), por mais irônico que soe tal assertiva, o textualismo forte como apreciação dos escritos se enquadra mais à direita que muitas pretensas políticas liberais que não se posicionam a favor de uma adoção do texto como elemento básico na interpretação jurídico-política.
}

Revista de Direito Brasileira | Florianópolis, SC | v. 22 | n. 9 | p. 50-65 |Jan./Abr. 2019 


\subsection{A Força Semântica da Hermenêutica Constitucional do Originalismo}

Assim, as cláusulas operativas são o núcleo central do conteúdo semântico, os elementos textualmente descritos dos quais o hermeneuta não pode se furtar em sua apropriação momentânea do texto constitucional, sob pena de se desviar daquilo que deve ser o resultado do seu norte interpretativo, preferindo interpretações alienígenas em detrimento da inquirição histórica contida na força semântica. Não obstante, a operabilidade (ou caráter operacional) das cláusulas constitucionais está descritas no texto e remetem à inquirição histórica, esse é o único conteúdo "não-escrito" que pode ser aceito nesse empreendimento interpretativo, pois, sem tal inquirição, tem-se apenas um aglomerado enunciativo, sem nenhuma força normativa propriamente dita.

A disjunção entre o aglomerado enunciativo "morto" e "sem operabilidade" e o resgate da inquirição histórica da pujança textual da Constituição é o que distingue o originalismo de um simples "legalismo hermenêutico estrito", que remete ao legalismo exegético do século XIX, no qual há uma mecanização do jurista em detrimento da letra da lei (HERNANDEZ GIL, 1945, p. 46). Não obstante, o originalismo prima por se distanciar de qualquer reprodução mecânica do Direito, haja vista que o sentido original repousa numa premissa tradicionalista e histórica bem distante de tal ideia de reprodutibilidade técnica.

Nessa esteira, Robert H. Bork (2009, p. 167) indica que:

A filosofia do sentido original não produz uma constituição rígida ou uma jurisprudência mecânica. Pelo contrário ela controla o processo de desenvolvimento da doutrina constitucional num modo que preserva a relevância e integridade da Constituição. É tarefa dos juízes da atual geração discernir como os valores fundadores, definidos no contexto do mundo que eles conheceram, aplicam-se ao mundo que nós conhecemos.

A força semântica da inquirição histórica no originalismo é o que o afasta da simples reprodução mecânica do conteúdo legal estritamente dado, assim, as cláusulas operativas do conteúdo semântico, a um só tempo, fazem desnecessárias as interpretações teleológicas de fundamentação exterior ao próprio texto, bem como fogem da armadilha de ter o texto pelo próprio texto, sem nenhuma outra fonte seguramente tradicional, que é o fundamento político-ideológico mais amplo do próprio originalismo.

Tomando-se por base que a prioridade mais elementar do originalismo é uma aderência fiel ao sentido original da Constituição, as implicações práticas para o conteúdo jurisdicional são contingentes à especificidade do texto em destaque e a sua história, ainda que, sem sucesso, alguns pensadores apontem a morte do originalismo (MALTZ, 1994, p. 15), tal indicativo é incorreto e falacioso. $\mathrm{O}$ originalismo aqui denotado está preocupado com o sentido convencionado por meio do texto, ou seja, o texto é o veículo que transporta o sentido a ser enunciado pelo hermeneuta, não há de se preocupar, portanto, com as expectativas sobre a aplicação do texto, ou acerca das esperadas consequências das provisões constitucionais, ou até mesmo sobre as motivações particulares para a adoção do texto fornecido (WHITTINGTON, 2013, p. 74). O originalista deve estar preocupado com a descoberta da regra ou do parâmetro principiológico constitucional que estava sendo adotado no momento da confecção do texto, e não como alguém, naquele dado momento histórico, esperava que a regra devesse ser aplicada ou o que os motivou a advogar pela adoção de tal regra.

Nesse ponto, deve ser feito uma sucinta distinção entre o que é a mera expectativa da aplicabilidade de uma regra ou um princípio constitucional, a qual variará de modo imprevisível e não uniforme, e aquilo que pode ser considerado o sentido original do texto constitucional, algo que só pode ser atingido por intermédio da inquirição histórica propriamente dita. A mera expectativa de aplicação de uma determinada regra ou princípio variará sempre de acordo com as preferências ou inclinações da sociedade (e do público alvo das diretrizes normativas), pois cada 
um, ao seu tempo, inclinar-se-á a apreciar uma ou outra questão de maneira diferente, influenciando, assim, a sua percepção sobre a matéria debatida. Essa variação temporal, efêmera e transitória, é algo que pode ser tido como problemático tanto pelos que defendem uma interpretação progressista do texto constitucional (e nesse arcabouço pode ser incluído qualquer um que advogue um entendimento que não seja originalista), quanto por aqueles que não conseguem distinguir o "sentido original" constitucional de qualquer outra forma interpretativa diversa, ainda que concomitante e contemporânea ao momento do desenvolvimento histórico-política da Constituição.

Inicialmente, para os críticos menos preparados ou para aqueles que detêm pouca familiaridade com a teoria originalista, pode parecer que o termo "sentido original" (ou "sentido originário", como por vezes referido) denota um engessamento da atuação do hermeneuta (ou do aplicador do Direito, de forma mais abrangente), tal como ocorre na exegese jurídica, por exemplo. Ou seja, como se o sentido original fosse algo fechado, engessado, pré-determinado, encapsulado e sem nenhuma margem de compreensão além daquilo que já está "simplesmente dado". Pelo contrário, a indeterminabilidade contida na inquirição histórica (ou melhor, dela derivada), é o veículo metodológico que previne o engessamento na interpretação do direito aos casos concretos (LIPKIN, 2000, p. 597). Ademais, não há vacuidade em tal indeterminação, haja vista que a operabilidade da cláusula constitucional que esteja em apreço, por meio do conteúdo semântico, garante que apenas os elementos que sejam necessários ao sentido original, e que não sejam com eles inconsistentes, podem estar afeitos a uma aplicabilidade direcionada ao caso concreto, sem que haja, portanto, contradições ou incoerências sistêmicas.

Nesse compasso, há de se depreender que o originalismo é uma teoria de interpretação constitucional que não agasalha um papel minimalista ao aplicador do direito, não reduzindo sua atividade a uma mera reprodução técnica e mecânica da letra da lei (PERRY, 2002, p. 206). A indeterminabilidade é um preceito fundamental para a inquirição histórica, mas seu núcleo de irradiação e de justificação não é propriamente histórico, e sim, epistêmico. Ou seja, justifica-se a indeterminabilidade através daquilo que ela possibilita ao hermeneuta conhecer do texto constitucional, e nele se fiando, de modo recíproco, por uma dinâmica mútua. Devido ao fato que o viés epistemológico da indeterminabilidade ser mais próximo de uma razoabilidade prática que de uma indeterminação metafísica vaga e puramente especulativa (LIPKIN, 2000, p. 596), a validação primária das regras e valores constitucionais (ínsitos ao sentido original) dá alguma margem optativa ao hermeneuta.

Aliás, mais do que simplesmente dar um modelo basilar, a indeterminabilidade em seu cunho epistêmico confere balizas sólidas e margens seguramente históricas para decisões e posicionamentos constitucionalmente atestados e a esse paradigma afeito. Diferentemente do posicionamento não-originalista que prima pela "verdade" do conteúdo "histórico-constitucional" (DWORKIN, 1986, p. 225), uma interpretação originalista epistemologicamente sólida encontra espeque no cerne semântico do seu sentido original. Desse modo, a verdade não é algo a ser dito pelo hermeneuta do texto constitucional, já que não se busca uma base de justificação metafísica para enunciar o conteúdo interpretativo constitucional (LIPKIN, 1992, p. 617), e, sim, algo empiricamente afeito ao conhecimento da história, e sua significância para a contextualização do sentido original buscado.

Assim, o escopo originalista possui sua força de expressão hermenêutica na possibilidade de importação semântica do sentido original para a interpretação hodierna de normas em contato com a Constituição. Manter o caráter perene na interpretação constitucional, garantindo-lhe solidez argumentativa e respaldo histórico é o intuito primordial do resgate semântico operado na metodologia originalista da leitura do texto constitucional, sempre lastreado por uma escorreita inquirição histórica do supramencionado sentido. 


\subsection{Inquirição Histórica e suas Derivações: Da Indeterminabilidade à Epistemologia Empírica}

A inquirição histórica, e por decorrência lógica, o sentido histórico, não buscam a uma "verdade"7 constitucionalmente prevalente, tais elementos se identificam mais com um campo de possibilidade decisórias que façam uma referência ao condensado tradicionalista que pode ser resgatado por meio de tal exercício hermenêutico. Essa variabilidade (ou margem de manobra decisória) é importante em dois aspectos, inicialmente pelo não engessamento, já mencionado anteriormente, e, em um segundo momento, por atrelar o sentido original a um paradigma políticojurídico específico, tal como se ele assume uma perspectiva de $\operatorname{comando}^{8}$ ao sentido original (BALKIN, 2014, p. 229). Não obstante, as circunstâncias de variação sempre farão referência a esse período da tradição, não podendo, porventura, lançar-se a empreendimentos progressistas ou alternativos que não possuam uma base epistemológica e histórica de relevante. De modo que qualquer possibilidade interpretativa que inove nas bases históricas ou visem dar uma conferência semântica diversa da contida no sentido original devem ser de plano espargida das possibilidades de análise, pois são espúrias e totalmente destoantes com as premissas inarredáveis da metodologia originalista em debate. $\mathrm{O}$ comando pós-determinado na inquirição histórica é o que garante uma possibilidade de interpretação ideológico-política em consentâneo com o sentido original tal qual ele está amalgamado na própria perspectiva epistemológica aí contida. Dito de uma maneira mais acrisolada, se há um conteúdo semântico que exprime um conhecimento específico e direcional na inquirição histórica, ele deve ser preservado no sentido original e transportado para a atualidade, preservando o que há de original no (con)texto constitucional e condicionando futuras interpretações a esse paradigma, que é prevalente e inegociável, sob o julgo do corretivo de malversação da própria Constituição, seja parcial ou totalmente tal emprego operado de forma indevida.

Ainda debatendo o que concerne à inquirição do sentido original e também no que diz respeito ao caráter histórico dessa inquirição, é de grande importância denotar, como o faz Michael J. Perry (1996, p. 70) que o hermeneuta originalista possui dois nortes em termos de inquirição: a inquirição interpretativa e a inquirição normativa. Justamente por não assumir (tampouco aceitar) um papel (ou uma atuação proativa) minimalista, ou seja, uma perspectiva segundo a qual o exercício de critérios judiciais torna-se insignificante, do texto constitucional que o originalismo necessita dessa bipartição em sua maneira de inquirir. Dito isso, e de acordo com as premissas da indeterminabilidade restrita à própria inquirição histórica, há de se chegar a dois elementos derradeiros.

O primeiro deles enuncia que com frequência, há mais de uma conclusão plausível dentro do sentido original de uma provisão constitucional valorativa, mais de uma conclusão judicativa pode ser alcançada pelo hermeneuta originalista, por causa dessa possibilidade dentro das plausibilidades que a inquirição histórica constitutiva da abordagem originalista é frequentemente indeterminada. Um termo temporal utilizado pelo autor em relevo (PERRY, 1996, p. 71) merece destaque, que é a noção de "frequência" (often, no original). Ele não enuncia, portanto, que sempre há indeterminabilidade na inquirição histórica, tampouco que há obrigatoriamente mais de uma opção fornecida nos limites estritos do sentido histórico. Quando ele se vale do termo frequente, ou do advérbio frequentemente, ele intenciona direcionar que em alguns casos, possivelmente na maioria deles, a inquirição histórica não se encapsula no próprio átimo histórico, e nem mesmo

\footnotetext{
${ }^{7}$ Por "verdade", deve-se depreender uma acepção metafísica absoluta e indiscutível. O sentido original não se prende a tal escrutínio de "verdade", e sim a um conhecimento (epistemologia empírica) do contexto histórico.

${ }^{8}$ Ainda que o autor mencionado (Balkin) tente se valer do termo comando, no intento de criticar o originalismo, assim como ocorreu com Brest, já mencionado, ambos acabaram por cunhar mais um termo que se adequa aos intentos originalistas, já que o comando nada mais é que uma derivação lógica e epistemologicamente válida da noção primordial de "sentido original", tão cara a esse método hermenêutico-constitucional.
}

Revista de Direito Brasileira | Florianópolis, SC | v. 22 | n. 9 | p.50-65 |Jan./Abr. 2019 
aprisiona o hermeneuta em sua futura interpretação (PETERS, 2015, p. 23). Todavia, o ponto basilar é a operabilidade e o direcionamento semântico contido no sentido original, de modo que não se podem fechar as possibilidades para que ele contenha uma única possibilidade interpretativa, afinal, frequentemente não induz ou aduz, de modo argumentativo, que sempre se faz mister ter mais que uma possibilidade de interpretação, principalmente quando uma segunda via interpretativa salte por fora do círculo hermenêutico do originalismo.

O outro ponto a ser levantado nessa abordagem da inquirição histórica diz respeito ao fato de que, havendo mais de uma possibilidade circunscrita no sentido original, ao menos uma delas (ou ela mesma, em caso de ocorrência unitária), também será, com frequência, indeterminada no que tange aos conflitos individualmente ofertados, ou seja, há alguma margem de manobra no que diz respeito aos casos concretos colocados em rota de confluência com o sentido original e com a inquirição histórica percorrida. Assim, os aspectos particulares de cada caso concreto podem vir a influenciar dentro do espectro de manobra concernente a inquirição histórica operada (embora, como se mostrará mais a frente, sua influência se dará mais na inquirição normativa que na inquirição interpretativa, sendo esta forma de inquirição atinente à inquirição normativa, e aquela mais destoante do resgate histórico a ser perquirido), sem, contudo, ser tal peculiaridade particular capaz de desfazer a configuração do sentido original por si mesmo. Dessa maneira, toda possibilidade de "aplicação constitucional" busca suplementar a confecção de regras e procedimentos para os quais o conteúdo concreto pode ser aplicado a casos particulares e controversos (BARNETT, 2013, p. 412). Todavia, essa aplicação constitucional deve, em todo caso, restringir-se ao sentido originalmente perquirido interpretativamente, não podendo estar dele apartado ou desconectado de forma alguma. Isto é, caso a particularidade do caso concreto seja tão destoante da inquirição histórica propriamente dita, ou o caso não deve ser apreciado segundo tais premissas, ou estar-se-á forçando uma abordagem progressista incabível aos fatos expostos.

A inquirição normativa, a seu turno, pode assumir uma perspectiva mais afeita ao pensamento de Hans-Georg Gadamer (1998, p. 403), na qual a compreensão de um texto legal não se compraz em sua aplicação, ou em sua imposição efetiva perante a realidade, sendo a distância entre o ato de compreender e o de aplicar onde reside a indeterminabilidade. Todavia, a perspectiva originalista prima pela indeterminabilidade normativa, que se não resolvida inteiramente no sentido original (perquirido na inquirição interpretativa), seja sanada através da aplicação do texto constitucional, sem que a possível diapasão entre compreensão e aplicabilidade debande, porventura, em interpretações falaciosas ou desconexas com a revisão histórica precedida em momento hermenêutico pretérito.

Nesse compasso, a premissa empírica da inquirição, seja ela interpretativa ou normativa, é que dá a tônica ao originalismo (BARNETT, 2013, p. 415), discorrendo objetivamente sobre um ponto específico do texto constitucional, reconstituindo seus fundamentos históricos, sem que, contudo, seja uma mera encenação das intenções subjetivas de um grupo de legisladores. A perspectiva empírica é necessária para que se afaste uma das críticas mais nefastas contra o originalismo, a que o condiciona a uma tentativa de destilar as intenções e entendimentos de um grande grupo de pessoas que não repartem uma única consciência coletiva apenas por meio de um "sentido" unitário posto num documento (LAWSON, 2012, p. 1558). Sem embargo, a perspectiva originalista assevera que o teste da evidência empírica no registro escrito é o único recurso legítimo do Direito Constitucional (O'NEILL, 2007, p. 112), sem ele qualquer interpretação pode ser feita ou pensada, do mesmo modo que qualquer erro se torna escusável, e, o pior de tudo, aceitável. Se não há balizas, tudo é aceito, e tudo é tomado como normal pela força da aceitação de sua falta de norteamento.

Assim, sem a denotação empírica do que o sentido original a ser resgatado e aplicado contemporaneamente ao texto constitucional perde-se em devaneios subjetivistas, o que não é, de forma alguma, o intento originalista em propor um viés tradicionalista e conservador à Constituição, tal como ela foi escrita e projetada. Dessa maneira, a interpretação originalista visa 
alcançar um elemento perene de legitimidade no texto constitucional e no contexto histórico que levou à construção desse texto fundamental.

\section{O ORIGINALISMO E SEUS ASPECTOS POLÍTICOS CONSERVADORES}

O sentido original, portanto, não é uma mera criação, ou de alguma maneira escamoteada, uma recriação, de um estado mental individual momentâneo, nem do hermeneuta (no presente), nem dos subscritores do texto constitucional (no caso do passado americano, dos "patriarcas", ou, no original, founding fathers). Caso o intento do originalismo fosse esse, a inquirição histórica seria um mero subterfúgio para que qualquer proposição progressista de interpretação fosse freada com base em uma mera perspectiva subjetivista sem qualquer lastro normativo, ou até mesmo sem nenhum lastro legal no sentido que o sentido original a ser buscado poderia subverter até mesmo a letra da lei tal e qual escrita. $\mathrm{O}$ argumento da impossibilidade de se chegar a uma inquirição histórica concernente com o sentido original (que, para os detratores do originalismo, sequer existe) tem o escopo primordial de deslegitimar metodologicamente o originalismo através da incerteza e do obscurantismo histórico (ou, melhor dizendo, o vetusto e controverso argumento que "a História é escrita pelos vencedores"). No entanto, o empenho empirista contido no âmago do originalismo solapa o pretenso argumento da falsa de legitimidade asseverando que somente o originalismo é capaz de fornecer uma legitimidade satisfatória ao texto constitucional sob dois aspectos: jurisprudencial e político (DELAHUNTY, p. 2010, p. 281). O aspecto jurisprudencial talvez seja o mais complicado de se compreender, em virtude das diferenças de formação histórica dos sistemas brasileiro e americano, já que a tradição romano-germânica predominante no Brasil obscurece um pouco tal concepção.

Ainda que esse ponto não seja tão relevante, quanto o aspecto político, o qual servirá de gancho para um aprofundamento subsequente no que concerne ao originalismo conservador propriamente dito, o aspecto jurisprudencial do originalismo veio tentar frear os impulsos personalistas e preferenciais do realismo jurídico prevalente nas cortes norte-americanas na década de 1970, ainda que o realismo se escondesse sob a fachada de um formalismo doutrinal, as cortes cada vez mais se rendiam às propostas progressistas de cunho individual, condicionadas pelos operadores do Direito. Ou seja, a "adequação" - ou adaptações cabíveis, através de uma "constituição viva"9 (STRAUSS, 2010, p. 26) - das normas ao "seu contexto atual" das cortes norte-americanas naquele momento chegou a um ponto inaceitável, em que ao dizer o Direito, os juízes estavam, em seu ativismo judicial (ELY, 1980, p. 10), criando, durante o exercício do controle de constitucionalidade, excrescências legais, sob o pretenso argumento que o Poder Judiciário está autorizado a fazer a lei evoluir em compasso com a sociedade.

$\mathrm{O}$ originalismo, nessa esteira, tal qual o devido processo legal preconiza, foi pensado para poder afirmar, criticamente, a legítima distinção entre a razão legal (ou o processo de enunciados racionalmente legais), que as cortes providenciam e a deliberação de políticas, que os ramos eleitos, Legislativo e Executivo fazem (DELAHUNTY, p. 2010, p. 283). Nessa toada, o segundo ponto que dá espeque ao originalismo em sua legitimidade diz respeito ao aspecto político dessa teoria de interpretação constitucional. Não é acidente enunciar que o originalismo usualmente vem acompanhado de uma "restrição" ou oposição ao intervencionismo ou ativismo judicial.

Por ser uma doutrina hermenêutica com aspectos políticos, o originalismo pretende revigorar a o processo político democrático. Assim, o originalismo procura remitir ou restaurar as possibilidades de decisão (decision making) para os processos eleitorais ou legislativos em um amplo espectro de casos complexos. Dessa feita, muito da força e da atração do originalismo deriva

\footnotetext{
${ }^{9}$ O termo usado no original é Living Constitution, e almeja dar uma dinâmica de mutabilidade e de evolução progressista às possibilidades hermenêuticas de se compreender, interpretar e aplicar a Constituição, ou seja, intenta investir progressivamente na interpretação do texto constitucional, sem nenhuma baliza histórica sólida.
}

Revista de Direito Brasileira | Florianópolis, SC | v. 22 | n. 9 | p.50-65 |Jan./Abr. 2019 
da crença tácita que há uma supremacia da política sobre a lei quando se trata de uma democracia constitucional (principalmente, em virtude das particularidades da estabilidade e do êxito da democracia norte-americana). Todavia, no que tange às possibilidades decisórias das cortes supremas, em matéria constitucional, sempre que se busca alguma escolha de valor, ela deve ser reminiscente ao sentido original do texto constitucional, e não aos próprios membros do órgão que prolatará a decisão (BORK, 1971, p. 4). O originalismo não se apresenta como uma prática política propriamente dita, já que ele não possui uma agenda que se compromete efetivamente com mudanças e proposições para o futuro. Ao contrário, o norte político (conservador) com o qual o originalismo se compromete está sempre fundamentado e alicerçado no sentido original da compreensão constitucional.

Sem embargo, o originalismo não é um comprometimento com influências do Poder Judiciário, por meio de suas decisões, no meio Legislativo ou Executivo, em posição diametralmente oposta, o originalismo se atém ao protecionismo das leis já existentes (e que estão em consentâneo com o próprio texto constitucional, e com seu sentido original, repise-se) e com a restrição da capacidade de inovação no ordenamento político através das decisões jurisdicionais. Contrapor-se a inovação do ordenamento jurídico é um dos estandartes do originalismo porque tal "inovação" com o fito de modificar ou buscar novos parâmetros fere mortalmente o texto constitucional, desdenhando de sua legitimidade sob o pretexto de "novas adequações sociais", vulgo "processo de mudanças sociais", as quais, teoricamente, não podem ser acompanhadas pelos Poderes que a ela estão mais diretamente vinculados (Legislativo e Executivo). O originalismo conservador é sempre cético com relação às intenções normativas e legislativas como um todo, de modo que essa posição hermenêutica não tende confiar cegamente nas propostas do Legislativo ou do Judiciário, mas, se alguma inovação há de ser feita na Constituição, que seja através de emendas, e não por meio da volição do operador do Direito, em seu pretenso progressismo jurídico ou eventualmente se calcando no realismo.

A restrição, nos moldes proposto pelo originalismo de viés conservador possui um enquadramento bijetor: é autorrestrição e restrição de posicionamento hierárquico (O'NEILL, 2007, p. 45) - da possível produção de uma lei através do processo legislativo ordinário perante a Constituição. Explicando de uma forma mais aprofundada, há de se compreender que a restrição proposta pelo originalismo não atinge apenas a atuação progressista dos magistrados em seu ofício, já que essa é a possibilidade de restrição mais clara. Ainda assim, essa forma de restrição deve ser tratada de forma propedêutica para que a segunda modalidade apresentada possa ser mais facilmente assimilada.

A autorrestrição pode ser enquadrada como uma verdadeira premissa de vedação ao ativismo judicial, já que busca impedir que os operadores do direito que sejam responsáveis pelos pronunciamentos jurisdicionais se valham de tal posicionamento técnico-político para impor, de forma unilateral e, consequentemente, antidemocrática, suas visões e suas preferências. Não respeitando, assim, nenhum embasamento técnico-constitucional em suas atuações marginais. Efetivamente, ocorre que os aplicadores da lei preferem optar por participar da policy-making a relegá-la ao talante de políticos e administradores. Ademais, em sua dinâmica, as decisões políticas do Judiciário (policy-making) implicam em um papel político mais positivo da decisão judicial do que aquele envolvido em uma "não decisão" (MACIEL; KOERNER, 2002, p. 114). Quando se tem um ativismo judicial presente, denota-se que o decision-making (ou a tomada de decisão) se torna um policy-making (política, ou atuação política) ${ }^{10}$, mas, não em um sentido genuíno de expressão política que qualquer cidadão pode ter, e, sim, no viés de uma atuação por

\footnotetext{
${ }^{10}$ Nesse enquadro, a tomada de decisão se vincula sempre a uma atuação política que não está em consentâneo com as premissas constitucionais propriamente ditas. Toda a tomada de decisão que implique em uma modificação do sentido original da força semântica contida na Constituição deve ser compreendida, por uma decorrência lógica, por inconstitucional, ou seja, uma atuação à margem do que a própria Constituição, a qual preconiza em seu sentido mais comezinho um norte dado a ela pela inquirição histórica.
} 
"politicagem"11, já que essa pretensa atuação política se dá fora dos meandros do sentido original inicialmente posto no cerne constitucional, algo que perpassa, indevidamente, toda a limitação de atuação legal desses agentes.

Restringir o ativismo judicial ${ }^{12}$ consiste em vedar a atuação pessoal e individual do agente em prol de políticas divergentes do sentido original professado no âmago constitucional. Se no Brasil há, particularmente, uma hipertrofia legislativa que dá azo ao ativismo judicial (VERBICARO, 2008, p. 390), no contexto constitucional do originalismo (da dinâmica norteamericana propriamente dita), o que se pretende evitar é uma hipertrofia jurisdicional, com decisões que sob o subterfúgio da adequação e do progresso social apenas são capazes de atingir o vilipêndio constitucional e a possibilidade de proliferação de decisões contraditórias e inconstitucionais. É possível se pensar que a autorrestrição se torna algo meramente quimérico pelo fato que os agentes políticos, por vezes, preferem (ou tencionam) que as decisões políticas mais delicadas e complicadas sejam tomadas por órgãos jurisdicionais (cortes constitucionais) ao invés de serem operadas em instâncias legislativas (WHITTINGTON, 2005, p. 583), como seria comum esperar. As intenções políticas por detrás dos bastidores ${ }^{13}$, por vezes, optam que decisões que afetem negativamente sua imagem sejam tomadas por um número restrito e bastante ínfimo de operadores do direito que nem sequer eleitos são em detrimento da possibilidade de arruinar negativamente o capital político conquistado por anos por uma determinada liderança política (quer ela integre o Poder Legislativo ou o Executivo, o dano a esse capital é sempre colossal).

A autorrestrição é a forma de restrição mais rápida e facilmente identificada com o originalismo, ainda que não seja prontamente aceita, sua compreensão é de fácil assimilação em termos conceituais, embora refratada em termos argumentativos. Já a segunda modalidade de restrição não é a facilmente identificável por quem não se dedica precipuamente ao estudo de tal tema porque, diferentemente da autorrestrição, ela não se direciona (diretamente ao menos) aos operadores do Direito, e sim para os outros atores do processo político-técnico, ou seja, os membros do Poder Legislativo e Executivo. O sentido original, mais uma vez, inclusive nesse ponto em específico, é salutar para a compreensão de como a restrição irradia-se do texto constitucional até os operadores do Direito (magistrados) e até para aqueles que estão encarregados da produção legislativa.

Como um dos intentos do originalismo consiste em não prover a inovação legal, essa função fica restrita aos demais Poderes (em específico ao Legislativo, ao Executivo, e ao próprio Judiciário, saliente-se, apenas atipicamente). Ou seja, se porventura houver algum descompasso entre o panorama social e alguma lei, somente o Legislativo será capaz de inovar no ordenamento e solucionar o impasse, não cabendo ao Judiciário intervir, e atuar de maneira proativa, como se fosse um ativista social. Ou seja, não podendo o membro do poder Judiciário legislar, caberá ao Poder competente atuar. Todavia, o Poder Legislativo, por seu turno, não poderá fugir das balizas dadas pela hermenêutica originalista, isto é, ele também está adstrito às premissas do sentido

\footnotetext{
${ }^{11}$ Pelo verbete exposto, deve-se depreender toda atuação com intuitos políticos, mas que foge do parâmetro ético mais simplório, qual seja atuar à margem do ordenamento jurídico positivado.

${ }^{12}$ Não há uma plena correspondência etimológica entre judicial restraint e judicial activism/judicial engagement (STRAUSS, 2011, p. 137). Todavia, há de se deixar assente que a perspectiva de restrição do originalismo não está atrelada a uma visão de judicial restraint que reprove toda e qualquer exposição política ou moral dos operadores do Direito, tal como o próprio Strauss aduz, já que ele acredita na possibilidade da "neutralidade" de atuação dos magistrados. Segundo o originalismo, tal como discorrido nesse trabalho, os juízes são órgãos técnico-políticos do Poder Judiciário, de modo que só se devem rejeitar os posicionamentos políticos que sejam contrários ao sentido original do texto constitucional, abrindo-se, portanto, a possibilidade de se abraçar o conservadorismo como enquadramento político-constitucional.

${ }^{13}$ De maneira bastante singular e pitoresca, de uma forma diferenciada e bastante diversa do que costuma ocorrer, Robert Bork foi rejeitado na sabatina do Senado americano por se posicionar de maneira originalista às formulações feitas a ele (BELTRÁ DE FELIPE, 1989, p. 31). Esse é um dos fatos históricos que legitimam a atuação política conservadora do originalismo nos meandros jurídico, tanto quanto o estandarte progressista serviu de bastião aos senadores no caso em relevo.
}

Revista de Direito Brasileira | Florianópolis, SC | v. 22 | n. 9 | p.50-65 |Jan./Abr. 2019 
original capturado na inquirição histórica, não podendo ele se furtar a obedecê-lo. Assim, não pode o Legislativo, nem mesmo sob a alegação de estar inovando o ordenamento jurídico, desprezar o sentido original e progredir em direção ao "anseio social”. Essa segunda forma de restrição possui uma dupla fundamentação. A primeira diz respeito à necessidade de obediência das novas leis à Constituição. Nesse momento, ao se falar de Constituição, não se está fazendo referência unicamente ao texto constitucional por si só, ou seja, está se falando de obediência à letra textual, bem como se está a referenciar a reverência obrigatória devida ao sentido original.

Há de se depreender, portanto, que o sentido original não possui influência e prevalência somente no que tange à possibilidade de um magistrado interpretar uma lei à luz do texto constitucional ou interpretar a Constituição por si mesma. $\mathrm{O}$ alcance do sentido original extrapola as cercanias da zona de contato com o Poder Judiciário e faz com que a restrição se estenda aos demais Poderes, cada um em seus próprios limites de inovação normativa. Não basta, portanto, que haja uma simples necessidade de adequação entre a situação fática e a lei (dada aqui no sentido mais amplo e genérico possível), é imperioso que a produção contida na inovação normativa respeite o sentido original contido no texto constitucional em apreço, à coima de nulidade plena, ou seja, de ser patentemente inconstitucional por não respeitar tal baliza inarredável à interpretação originalista. No compasso dado, a projeção semântica das cláusulas operativas ínsitas aos comandos constitucionais afeitos ao sentido original nele contido é espargida para além das esferas aparentemente pensadas ou usualmente concebidas.

Por causa de todo o contexto restritivo e de resgate histórico ínsito ao originalismo, é deveras condizente asseverar que essa perspectiva hermenêutica, em maior ou menor monta, dependendo de qual abordagem tomada, conduz sempre ao conservadorismo ou a resultados conservadores, por assim dizer (STRANG, 2011, p. 286). Por conservadorismo (atrelado ao originalismo), deve-se compreender a filosofia política de Russel Kirk (2001, p. 9), que possui dois estandartes (ambos já mencionados no decorrer do texto, embora apenas agora citados diretamente): preservação de normas tradicionais de conduta humana e a prescrição normativa para indivíduos e para a sociedade que recaiam sob o paradigma conservador. Por conservadorismo, nessa mesma medida, deve-se compreender a oportunidade de viver nossas vidas como se almeja (princípio básico de liberdade), a segurança da lei imparcial, a reparação de danos e os procedimentos democráticos que permitem eleger representantes e aprovas as próprias leis (SCRUTON, 2015, p. 9). Nessa toada, a retomada histórica do sentido original preserva o estandarte conservador de normas que não deveriam ser vilipendiadas hodiernamente e, de maneira concomitante, o originalismo traça parâmetros conservadores para o desenvolvimento da normativa vindoura (quiçá por intervenções constitucionais por emenda, como é o caso da segunda emenda norte-americana, a que garante a posse e o porte de armas à população). Assim, os costumes, as convenções e as antigas prescrições (comportamentais), que são os veículos de propagação e manutenção do ideal conservador, são uma pedra no caminho dos impulsos anárquicos do homem e sobre a luxúria pelo poder dos inovadores (progressistas).

Por fim, há de se indicar que o originalismo possui uma veia conservadora bastante evidente, a qual busca encontrar na própria guarida constitucional uma fonte de legitimação. Somente através do viés claramente democrático ínsito na legitimidade constitucional explicitada que o originalismo retém seus esforços em promover uma proteção aos avanços obtusos do realismo jurídico e da progressividade em geral, da mesma maneira que guarda a mais alta estima pela defesa dos estandartes constitucionais. 


\section{CONSIDERAÇÕES FINAIS}

Conclusivamente, em um breve fechamento do tema debatido ao longo do desenvolvimento em tela, deve-se indicar que o originalismo, ainda que não seja uma corrente conceitualmente unitária, tende, precipuamente, a um entendimento legitimamente posto do texto constitucional. Sua busca pelo encontro do sentido original e consequentemente demanda por uma proteção dos estandartes constitucionais o levam a sempre ter uma centelha conservadora em sua abordagem.

Todavia, o originalismo não tende a recair em uma falta de legitimidade subjetivista ou em um minimalismo exegético, como podem querer argumentar os seus detratores. A legitimidade hermenêutica do originalismo corresponde fielmente ao apego ao texto constitucional, e, por conseguinte, ao sentido original nele transcrito, haja vista que, por meio da inquirição histórica, empírica e epistemologicamente lastreada nas balizas da possibilidade da indeterminação contida, garante uma margem de interpretação razoável. Assim, o operador do direito consegue chegar ao conhecimento empírico do sentido original, não vagueando tontamente por "expectativas" de aplicação que poderiam envolver o contexto da época. Ademais, pela própria fundamentação da inquirição histórica (em seus aspectos normativos e interpretativos), existe uma margem de contorno hermenêutico dentro da interpretação originalista que não a amarra a seara exegética, diferenciando-o do minimalismo ou do estrito legalismo jurídico.

De forma derradeira, há de se indicar que o escorço de legitimidade erguido em prol do originalismo, que se ancora, justamente, no texto constitucional e na inquirição histórica que o orbita, abre a possibilidade de se analisar os vieses políticos daí advindos. Como já reiterado em várias passagens desse trabalho, o originalismo sempre trabalha com uma perspectiva conservadora em seus intentos, desde o resgate do sentido histórico até a concreta conceituação dos limites de decisão jurisdicionais, todos os aspectos que envolvem Direito e Política se imbricam nesse nó górdio do conservadorismo no âmbito jurídico. Todavia, em respeito ao próprio texto constitucional o originalismo outorga limites de restrição e de autorrestrição para que o exercício das premissas conservadoras seja efetuado. Todos esses parâmetros são fundamentais, não apenas para conhecer o originalismo em sua vertente conservadora, como também para que se possa observar sua efetiva atuação nos casos ligeiramente mencionados de suas tratativas na supre-corte norte-americana.

\section{REFERÊNCIAS}

BALKIN, Jack M. Living Originalism. Cambridge: Harvard University Press, 2014.

BARNETT, Randy E. The Gravitational Force of Originalism. Georgetown Law Faculty Publications. v. 82, n. 2, 2013.

BELTRÁN DE FELIPE, Miguel. Originalismo e Interpretación. Madrid: Civitas, 1989.

BENNETT, Robert W.; SOLUM, Lawrence. Constitutional Originalism: A Debate. Ithaca: Cornell University Press, 2016.

BORK, Robert H. A Time do Speak: Selected Writings and Documents. Wilmington: Isis Books, 2009. 
BORK, Robert H. Neutral Principles and Some First Amendment Problems. Indiana Law Journal. v. 47, v.1, 1971.

BREST, Paul. The Fundamental Rights Controversy: The Essential Contradictions of Normative Constitutional Scholarship. Yale Law Journal. v. 90, n. 5, 1981. p. 1063-1109.

DELAHUNTY, Robert J. Response, Originalism and Legitimacy: A Reply to Professor Powell, University of St. Thomas Law Journal. v. 7, n. 2, 2010.

DWORKIN, Ronald. Law's Empire. Cambridge: Harvard University Press, 1986.

ELY, John Hart. Democracy and Distrust: A Theory of Judicial Review, Harvard University Press, 1980.

ESKRIDGE, William N. Jr. The New Textualism and Normative Canons. Columbia Law Review. v.113, n. 1, 2013.

GADAMER, Hans-Georg. Verdade e Método. 2. ed. Tradução de Flávio Paulo Murer. Petrópolis, Vozes, 1987.

GOLDFORD, Dennis J. The American Constitution and the Debate Over Originalism. Cambridge: Cambridge University Press, 2005.

HERNANDEZ GIL, Antonio. Metodologia del Derecho. Madrid: Revista de Derecho Privado, 1945.

KIRK, Russell. The Conservative Mind: From Burke to Eliot. 7. ed. Washington, D.C.: Regnery Pub, 2001.

LAWSON, Gary. No History, No Certainty, No Legitimacy... No Problem: Originalism and the Limits of Legal Theory, Florida Law Review, v. 64, 2012.

LIPKIN, Robert Justin. Constitutional Revolutions: Pragmatism and the Revolutionary Role of Judicial Review in American Constitutionalism. Durham: Duke University Press, 2000.

LIPKIN, Robert Justin. Indeterminacy, Justification and Truth in Constitutional Theory, Fordham Law Review. v. 60, n. 4, 1992.

MACIEL, Débora Alves; KOERNER, Andrei. Sentidos da Judicialização da Política: duas análises. Lua Nova, n. 57, 2002.

MALTZ, Earl M. Rethinking Constitutional Law: Originalism, Interventionism, and the Politics of Judicial Review. University Press of Kansas, 1994.

O'NEILL, Johnathan G. Originalism in American Law and Politics: A Constitutional History. Johns Hopkins University Press, 2007.

PERRY, Michael J. The Constitution in the Courts: Law or Politics? Oxford: Oxford University Press, 1996. 
PERRY, Michael J. We the People: The Fourteenth Amendment and the Supreme Court. Oxford: Oxford University Press, 2002.

PETERS, Christopher J. Legal Formalism, Procedural Principles and Judicial Constraint in American Adjudication. PINESCHI, Laura (Org.). General Principles of Law: The Role of the Judiciary. New York: Springer, 2015.

PRIMUS, Richard A. When Should Original Meanings Matter? Michigan Law Review. V. 107, n. 2, 2008.

SCALIA, Antonin. A Matter of Interpretation: Federal Courts and the Law. Princeton: Princeton University Press, 2016.

SCALIA, Antonin. Originalism: The Lesser Evil. University of Cincinnati Law Review. v. 57, n. $1,1989$.

SCALIA, Antonin; GARNER, Bryan A. Reading Law: The Interpretation of Legal Texts. St. Paul, MN: Thomson, 2012.

SCRUTON, Roger. Como ser um Conservador. Tradução de Bruno Garschagen e Márcia Xavier de Brito. Rio de Janeiro: Record, 2015.

STRANG, Lee J. Originalism as Popular Constitutionalism: Theoretical Possibilities and Practical Differences. Notre Dame Law Review. v. 87, n.1, 2013.

STRAUSS, David A. Originalism, Conservatism, and Judicial Restraint. Harvard Journal of Law and Public Policy. v. 34, n.1, 2011.

STRAUSS, David A. The Living Constitution. New York: Oxford, 2010.

VERBICARO, Loiane Prado. Um Estudo sobre as Condições Facilitadoras da Judicialização da Política no Brasil. Revista Direito GV, n. 4, 2008.

WHITTINGTON, Keith E. Interpose Your Friendly Hand: Political Supports for the Exercise of Judicial Review by the United States Supreme Court. American Political Science Review, v. 99, n. 4, 2005.

WHITTINGTON, Keith E. Is Originalism Too Conservative? Harvard Journal of Law \& Public Policy. v. 34, n .1, 2011.

WHITTINGTON, Keith E. On Pluralism Within Originalism. In: HUSCROFT, Grant; MILLER, Bradley W. (Orgs.). Challenge of Originalism: Theories of Constitutional Interpretation. Cambridge: Cambridge University Pres, 2013. 